УДК 338.1

$10.17213 / 2075-2067-2020-5-152-161$

\title{
ОЦЕНКА ВЛИЯНИЯ СНИЖЕНИЯ НАЛОГОВОЙ НАГРУЗКИ НА БИЗНЕС В ПЕРИОД ПАНДЕМИИ НА ФОРМИРОВАНИЕ ДОХОДОВ БЮДЖЕТА РОССИЙСКОЙ ФЕДЕРАЦИИ В 2020 Г.
}

\author{
(C) 2020 г. . В. Гашенко, Ю. С. Зима, А. К. Мусаелян \\ Ростовский государственный экономический университет (РИНХ), \\ 2. Ростов-на-Дону, Россия
}

Цель исследования. $B$ статье проводится оченка влияния снижения налоговой нагрузки на бизнес в период пандемии на формирование доходов бюджета РФ в 2020 г.

Методы исследования. Исследование опирается на материаль существующих работ по теме налогообложения предпринимательства и его специфики в условиях экономических кризисов. В качестве методического обеспечения исследования используется метод сравнительного анализа налоговых доходов и налоговой нагрузки в условиях стабильности экономики России.

Результаты исследования. На основе изучения опыта изменения налоговой нагрузки на бизнес в России в 2011-2019 г2. определена величина требуемого снижения данной нагрузки в 2020 г. для выполнения плана федерального бюджета Российской Федерации. Проведен план-фактный анализ этого бюджета и сделан вывод о достаточности осуществленного снижения налоговой нагрузки для бизнеса и перспективах дальнейтего использования механизма налогообложения в интересах кризис-менеджмента в России в период кризиса 2020 г.

Перспективы использования результатов исследования. Исследование открывает широкие перспективы дальнейшего использования механизма налогообложения в интересах кризис-менеджмента в России и подчеркивает целесообразность и эффективность сохранения введенных налоговых преференций и возможность их увеличения, а также распространения налоговых преференций и льгот на больший перечень бизнес-структур.

Ключевые слова: налоговая нагрузка; субъекты предпринимательства; налоговые доходы; оцифровка налоговых процессов; налоговые льготы и преференции; налоговое регулирование; экономические показатели доходов бюджета; экономический рост; совершенствование инструментов налогового регулирования.

\section{ASSESSMENT OF THE IMPACT OF REDUCING THE TAX BURDEN \\ ON BUSINESS DURING A PANDEMIC ON THE FORMATION OF BUDGET REVENUES RUSSIAN FEDERATION IN 2020}

\author{
(C) 2020 I. V. Gashenko, J. S. Zima, K. A. Musaelian
}

Rostov State University of Economics (RSUE), Rostov-on-Don, Russia

Purpose of research. The article assesses the impact of reducing the tax burden on business during the pandemic on the formation of budget revenues in the Russian Federation in 2020. 
Method of research. The research is based on the materials of existing works on the topic of taxation of entrepreneurship and its specifics in the context of economic crises. The method of comparative analysis of tax revenues and tax burden in the conditions of stability of the Russian economy is used as a methodological support for the study.

Research result. Based on the study of the experience of changes in the tax burden on businesses in Russia in 2011-2019, the amount of the required reduction in this burden in 2020 for the implementation of the Federal budget plan of the Russian Federation is determined. The planfact analysis of this budget is carried out and the conclusion is made about the sufficiency of the implemented reduction of the tax burden for business and the prospects for further use of the tax mechanism in the interests of crisis management in Russia during the crisis of 2020.

Prospects for using the research results. The study opens up broad prospects for further use of the tax mechanism in the interests of crisis management in Russia and emphasizes the feasibility and effectiveness of maintaining the introduced tax preferences and the possibility of increasing them, as well as extending tax preferences and benefits to a larger list of business structures.

Key words: tax burden; business entities; tax revenues; digitization of tax processes; tax benefits and preferences; tax regulation; economic indicators of budget revenues; economic growth; improvement of tax regulation tools.

Введение. Пандемия COVID-19 вызвала экономический кризис, уникальный не только по своей природе (кризис начался в здравоохранении и вызвал тотальные ограничения практически во всех остальных сферах), но и по своему масштабу — кризис 2020 г. еще далек от завершения, но уже превзошел финансово-экономический кризис 2008 г. по глубине спада и охвату экономики. Специфичность нынешнего кризиса также распространяется на его сущность и возможности его преодоления. Так, финансово-экономический кризис 2008 г. можно назвать стандартным, типичным. Это был кризис перепроизводства, при котором стимулирование спроса, в частности, с помощью увеличения доходов населения, способствовало росту продаж, ускорению экономического роста и соответственно преодолению кризиса.

В условиях пандемии рыночный спрос сократился не только из-за падения доходов, но и, что гораздо серьезнее, из-за ограничений социального взаимодействия, распространившихся и на предпринимательство, вызвав спад предложения на рынке, поэтому традиционно применяющийся неокейнсианский подход к преодолению кризиса через размещение инвестиций в экономику (в широком смысле) обладает ограниченным антикризисным потенциалом и недостаточен для выхода из кризиса. Все это потребовало научного поиска нового подхода к решению проблемы формирования доходов бюджета Российской Федерации в условиях социально-экономического кризиса 2020 г.

Рабочая гипотеза данного исследования состоит в том, что важную роль в формировании доходов бюджета Российской Федерации в первой половине 2020 г. сыграло снижение налоговой нагрузки на бизнес, которое было заложено в правительственном антикризисном плане по государственной поддержке экономики граждан во время пандемии на 2020-2021 гг. и в пост-пандемийный период. Целью статьи является оценка влияния снижения налоговой нагрузки на бизнес на формирование доходов бюджета Российской Федерации в период пандемии 2020 г.

Методы. Это исследование опирается на материалы существующих работ по теме налогообложения предпринимательства и его специфики в условиях экономических кризисов таких авторов, как А. Ю. Бунина, Т.Н. Павлюченко [3], Ю. Джабраилов [8], Н.Ц. Павлова, Б.С. Микуляева [11], С.Н. Фирсова, М.Н. Глухова, Ю.И. Ильясова [15], а также на собственные исследования авторов, представленные в опубликованных работах $[4,5,6$, 17]. В работе также используются материалы трудов по теме формирования государственного бюджета Российской Федерации в усло- 
виях кризиса и, в частности, в 2020 г. таких ученых, как С.Г. Белёв, Т.В. Тищенко [1], А.Н. Дерюгин [7], С.П. Колчин, Н. Ю. Глубокова [10], И. Е. Смирнов [12], Ю.С. Тагильцева [13], Л. Г. Чередниченко, А. З. Селезнев [16].

В качестве методического обеспечения исследования используется метод сравнительного анализа налоговых доходов и налоговой нагрузки в условиях стабильности экономики России в 2011-2019 гг., а затем в условиях кризиса 2020 г. - метод корреляционно-регрессионного анализа.

Логической составляющей выдвинутой гипотезы является определение влияния налогообложения на формирование доходной части государственного бюджета.

В качестве информационно-эмпирической базы исследования выступают материалы Всемирного экономического форума, содержащиеся в Отчетах о глобальной конкурентоспособности за 2011-2019 гг. [18] и отражающие динамику налоговой нагрузки в России в указанный период с помощью таких показателей, как влияние налогообложения на инвестиции и налоговая нагрузка на бизнес. Также используются материалы о налоговых дохо- дах государственного бюджета в соответствии с официальной статистикой Министерства финансов Российской Федерации [9]. Исходные данные для проведения исследования сосредоточены в табл. 1 (составлено авторами на основе материалов $[9,18])$.

Результаты. Оценка влияния налоговой нагрузки на бизнес на формирование доходов бюджета РФ в 2020 г. произведена с помощью построения регрессионных кривых на рис. 1-3 (рассчитано и построено авторами).

Согласно рис. 1 налоговые платежи по внутреннему НДС в России в 20112019 гг. в значительной степени (корреляция $87,15 \%$ ) определяются влиянием налогообложения на инвестиции, увеличение которого на 1 балл приводит к росту налоговых поступлений по внутреннему НДС на 2725,7 млрд. руб. Корреляция с налоговой нагрузкой на бизнес $(25,85 \%)$ пренебрежительно мала.

Согласно рис. 2 налоговые платежи по НДС на ввозимые товары в Россию в 20112019 гг. не зависят от налоговой нагрузки на бизнес, так как коэффициенты корреляции

Таблица 1

Статистика налоговой нагрузки и налоговых доходов федерального бюджета Российской Федерации в 2011-2019 гг.

\begin{tabular}{|c|c|c|c|c|c|}
\hline \multirow{3}{*}{ Год } & \multirow{2}{*}{$\begin{array}{c}\text { Влияние налогообложения } \\
\text { на инвестиции, баллы 1-7 } \\
\text { [в 2013-2017 гг.: Effect of taxation } \\
\text { on incentives to invest } \\
\text { (в 2011-2012 г.: Extent } \\
\text { and effect of taxation)] }\end{array}$} & \multirow[b]{2}{*}{$\begin{array}{l}\text { Налоговая нагрузка } \\
\text { на бизнес, \% } \\
\text { [в 2011-2017 гг:: } \\
\text { Total tax rate, } \\
\text { \% profits] }\end{array}$} & \multicolumn{3}{|c|}{ Налоговые платежи: } \\
\hline & & & \multirow{2}{*}{ 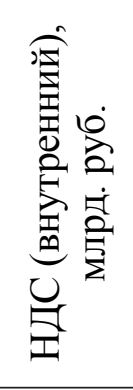 } & \multirow{2}{*}{ 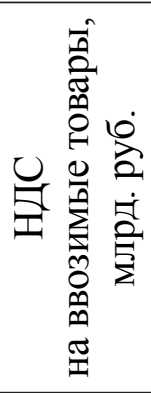 } & \multirow{2}{*}{ 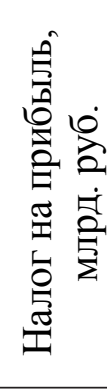 } \\
\hline & \multicolumn{2}{|c|}{$\begin{array}{c}\text { Влияние налогообложения на конкуренцию } \\
\text { [в 2018-2019 гг:: 01 Distortive effect of taxes } \\
\text { and subsidies on competition] }\end{array}$} & & & \\
\hline 2011 & 3,1 & 46,5 & 1753,2 & 1497,2 & 342,6 \\
\hline 2012 & 2,9 & 46,9 & 1886,1 & 1659,7 & 375,8 \\
\hline 2013 & 3 & 54,1 & 1868,2 & 1670,8 & 352,2 \\
\hline 2014 & 3,1 & 50,7 & 2181,4 & 1750,2 & 411,3 \\
\hline 2015 & 3,1 & 48,9 & 2448,3 & 1785,2 & 491,4 \\
\hline 2016 & 3,1 & 47 & 2657,4 & 1913,6 & 491 \\
\hline 2017 & 3,2 & 47,4 & 3069,9 & 2067,2 & 762,4 \\
\hline 2018 & 3,6 & 44,2 & 3574,6 & 2442,1 & 995,5 \\
\hline 2019 & 3,8 & 46,6 & 4257,8 & 1837,4 & 1185 \\
\hline
\end{tabular}


пренебрежительно малы $(32,27 \%$ и $23,85 \%)$. Это подтверждает научно-экономическое обоснование выявленной связи между внутренним НДС и налоговой нагрузкой на бизнес (рис. 1) и исключает влияние НДС на ввозимые товары на уровень налоговой нагрузки на российский бизнес и инвестиции.

Согласно рис. 3 поступления по налогу на прибыль в России в 2011-2019 гг. в значи- тельной степени (корреляция 91,28\%) определяются влиянием налогообложения на инвестиции, увеличение которого на 1 балл приводит к росту платежей по налогу на прибыль на 1005 млрд. руб. Корреляция с налоговой нагрузкой на бизнес $(28,43 \%)$ достаточно низкая.

В первом полугодии 2020 г. для снижения налоговой нагрузки на бизнес в России
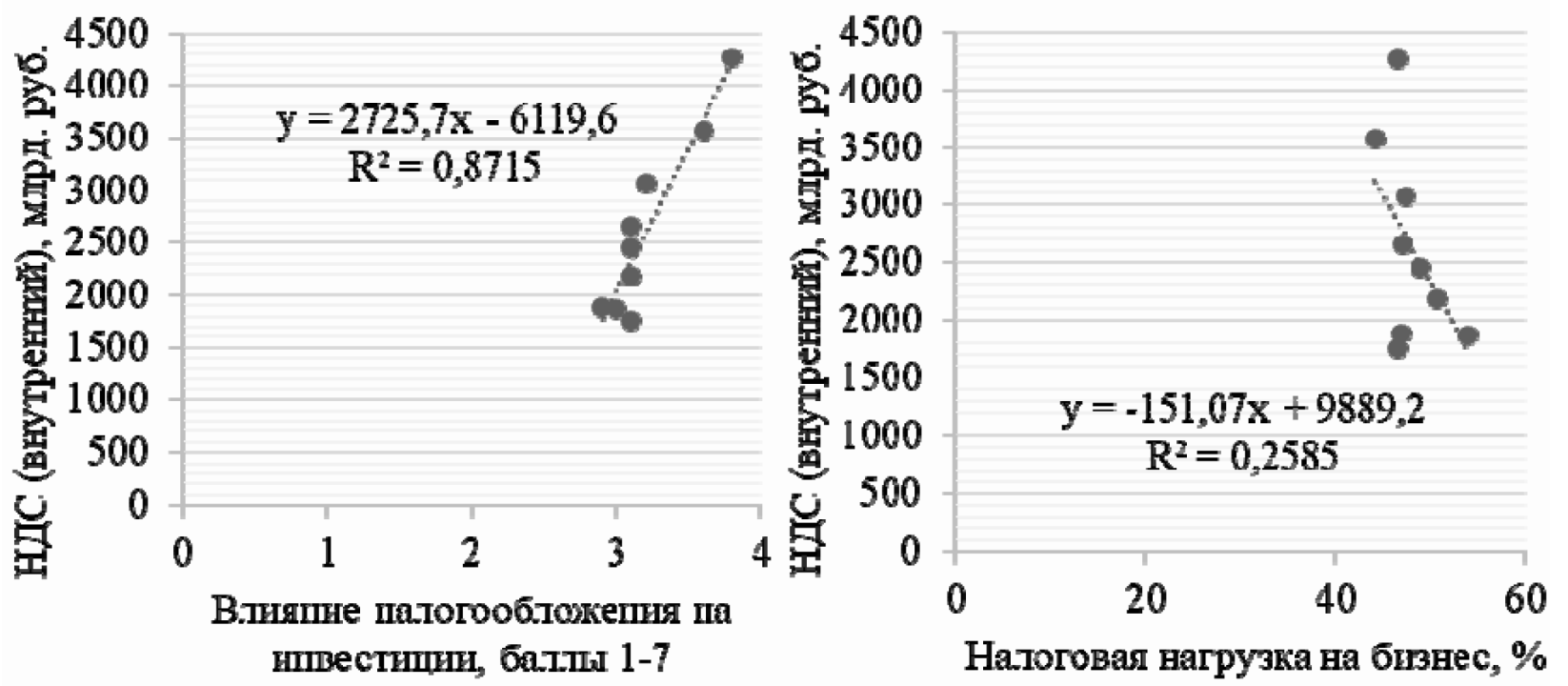

Рис. 1. Регрессионная кривая зависимости налоговых сборов по внутреннему НДС от налоговой нагрузки на бизнес в России в 2011-2019 гг.
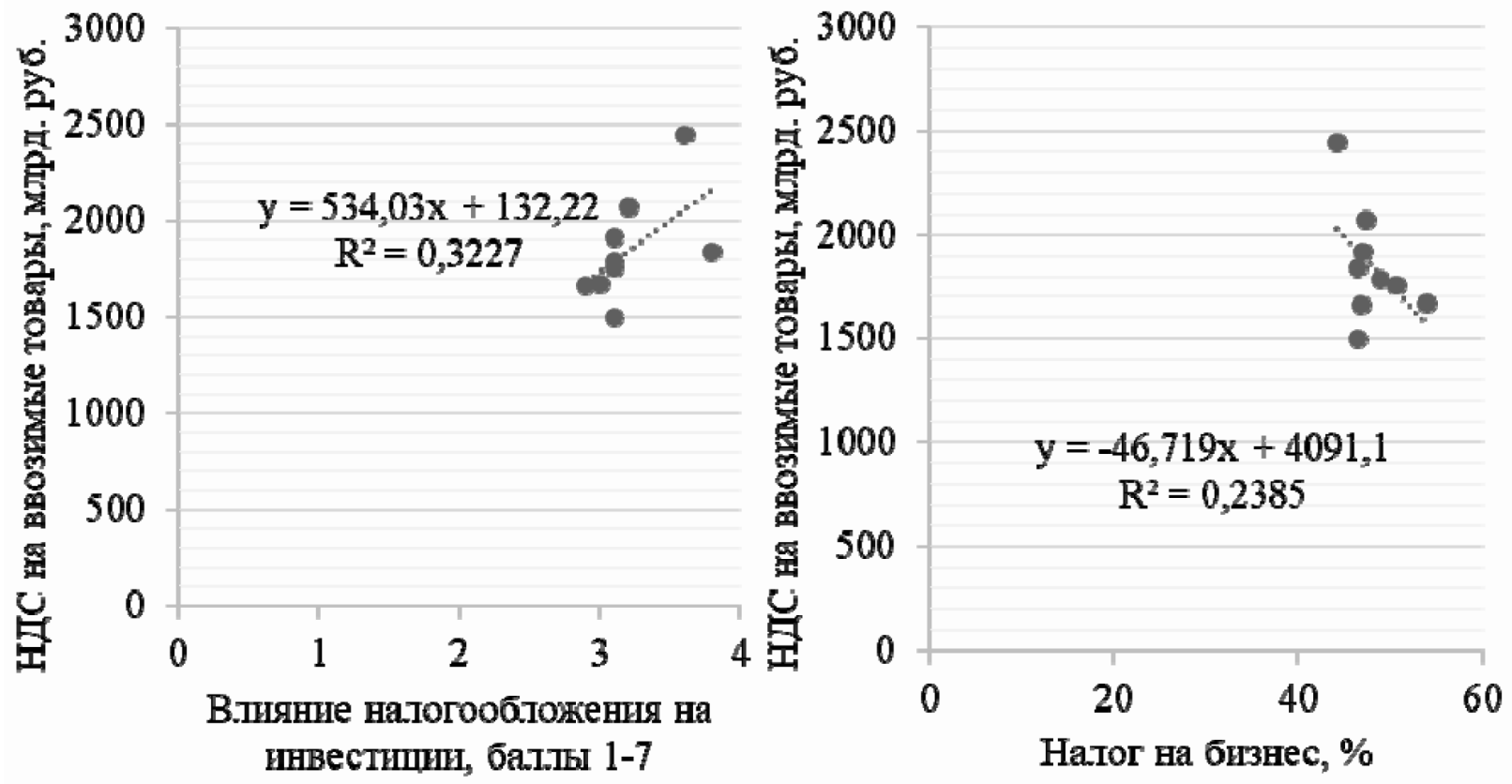

Рис. 2. Регрессионная кривая зависимости налоговых сборов по НДС на ввозимые товары от налоговой нагрузки на бизнес в России в 2011-2019 гг. 
Таблица 2

План-фактный анализ доходов федерального бюджета РФ за I полугодие 2020 года, млн. руб.

\begin{tabular}{|c|c|c|c|c|}
\hline Показатель & \begin{tabular}{|c|} 
Федеральный закон \\
«О федеральном \\
бюджете на \\
2020 год и на \\
плановый период \\
2021 и 2022 годов»
\end{tabular} & $\begin{array}{c}\text { Прогноз } \\
\text { доходов на } \\
\text { I полугодие } \\
2020 \text { года }\end{array}$ & $\begin{array}{c}\text { Отчет за } \\
\text { I полугодие } \\
2020 \text { года }\end{array}$ & $\begin{array}{c}\text { Отклонение } \\
\text { фактических } \\
\text { поступлений } \\
\text { от прогноза } \\
\text { на I полугодие } \\
2020 \text { года }\end{array}$ \\
\hline Доходы & 20593572,90 & 7744872,10 & 9091870,60 & 1346998,50 \\
\hline в \% $\% B B \Pi$ & 18,1 & 15,8 & 18,6 & 2,8 \\
\hline Нефтегазовые доходы & 7523778,60 & 2602496,10 & 2661046,80 & 58550,70 \\
\hline в \% $\%$ ВBП & 6,6 & 5,3 & 5,4 & 0,1 \\
\hline Ненефтегазовые доходы & 13069794,20 & 5142376,10 & 6430823,80 & 1288447,70 \\
\hline в \% $\%$ BBП & 11,5 & 10,5 & 13,1 & 2,6 \\
\hline $\begin{array}{l}\text { Связанные с внутренним } \\
\text { производством }\end{array}$ & 6730696,60 & 2840534,50 & 3028308,50 & 187774,00 \\
\hline НДС внутренний & 4552792,70 & 1969212,30 & 2078599,70 & 109387,40 \\
\hline Акцизы внутренние & 960593,10 & 393120,80 & 412898,60 & 19777,80 \\
\hline Налог на прибыль & 1217310,80 & 478201,40 & 536810,20 & 58608,80 \\
\hline Связанные с импортом & 3811481,50 & 1515932,10 & 1586235,80 & 70303,70 \\
\hline НДС ввозной & 3020508,00 & 1178482,90 & 1255098,70 & 76615,80 \\
\hline Акцизы ввозные & 125916,60 & 40188,10 & 42157,30 & 1969,20 \\
\hline $\begin{array}{l}\text { Ввозные таможенные } \\
\text { пошлины }\end{array}$ & 665057,00 & 297261,10 & 288979,80 & $-8281,30$ \\
\hline $\begin{array}{l}\text { Прочие ненефтегазовье } \\
\text { доходы }\end{array}$ & 2527616,10 & 785909,50 & 1816279,50 & 1030370,00 \\
\hline
\end{tabular}

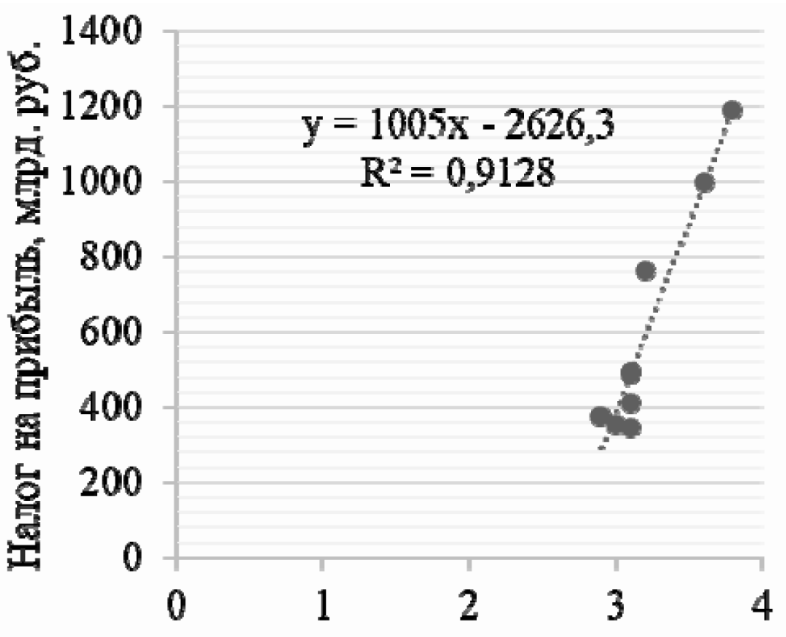

В.тияние натогообтоженчя на инвестиши, балты 1-7

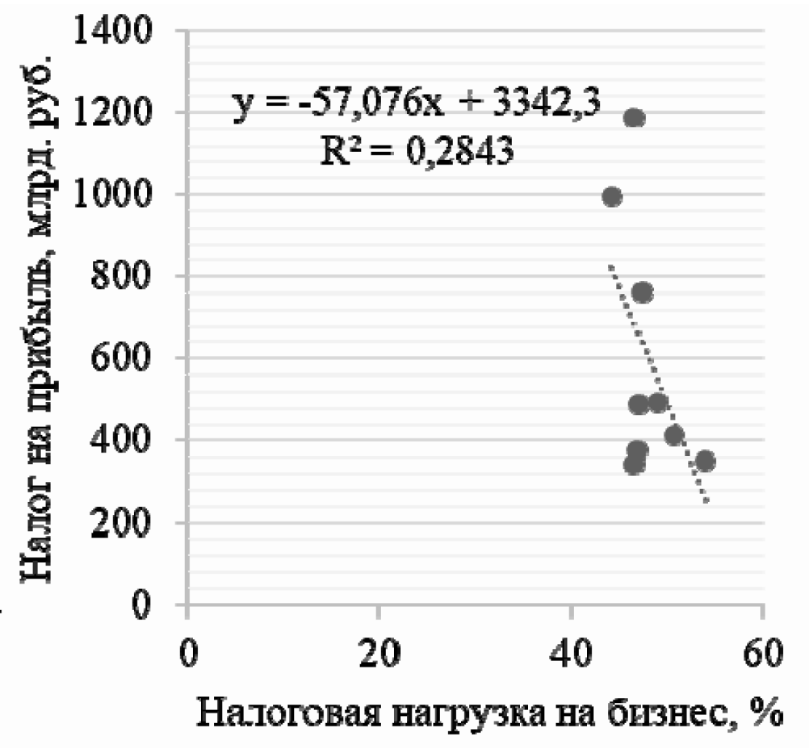

Рис. 3. Регрессионная кривая зависимости налоговых поступлений по налогу на прибыль от налоговой нагрузки на бизнес в России в 2011-2019 гг. 
по причине пандемии были предприняты следующие антикризисные меры [2]:

- индивидуальным предпринимателям, субъектам малого и среднего предпринимательства и некоммерческим организациям в наиболее подверженных кризису отраслях были предоставлены отсрочки по уплате некоторых налогов (страховые взносы во внебюджетные фонды и НДФЛ, акцизы, НДПИ, налог на прибыль, налог на имущество, земельный налог, единый налог по специальным налоговым режимам - УСН, ЕСХH, ЕНВД и др.);

- продлены сроки сдачи налоговой отчетности для субъектов малого и среднего бизнеса (за исключением НДС);

- приостановлены налоговые проверки, процедуры взыскания налоговой задолженности;

- введение моратория на возбуждение дел о банкротстве для налогоплательщиков.

Принятые меры умеренно способствовали увеличению налоговых преференций для российского предпринимательства по сравнению с иностранными конкурентами (мера протекционизма), что подчеркивает необходимость снижения налоговой нагрузки на бизнес в период пандемии.

Чтобы оценить влияние снижения налоговой нагрузки на бизнес в период пандемии на формирование доходов бюджета РФ в 2020 г., проведем план-фактный анализ доходов бюджета (табл. 2 (составлено авторами на основе материалов [14])).

Для достижения целевых (плановых) значений налоговых платежей по внутреннему НДС (4552,79 млрд. долл.) и по налогу на прибыль (1217,31 млрд. руб.) в 2020 г. влияние налогообложения на инвестиции должно возрасти с 3,8 до 3,92 баллов (предположительно), то есть на 3,16\% по сравнению с 2019 г.

Результаты план-фактного анализа данных из табл. 2 показали, что план бюджета перевыполнен для большинства показателей. К примеру, фактические сборы по внутреннему НДС оказались больше плана на 109387,4 млн. руб., а по налогу на прибыль - на 58608,8 млн. руб. Это доказывает выраженное положительное влияние снижения налоговой нагрузки на бизнес в период пандемии на формирование доходов бюджета РФ в 2020 г, обеспечивающего такие преимущества, как де-теневизация бизнеса, сохранение бизнеса (предотвращение критических убытков и банкротства), а также обеспечение пополнения федерального государственного бюджета.

Заключение. Таким образом, проведенное исследование свидетельствует о том, что выдвинутая гипотеза подтверждена. Снижение налоговой нагрузки на бизнес в период пандемии оказало выраженное положительное влияние на формирование доходов бюджета РФ в 2020 г. Это открывает широкие перспективы дальнейшего использования механизма налогообложения в интересах кризис-менеджмента в России и подчеркивает целесообразность и эффективность сохранения введенных налоговых преференций и возможность их увеличения, а также распространения налоговых преференций и льгот на больший перечень бизнес-структур.

\section{Литература}

1. Белёв С.Г. Исполнение федерального бюджета в январе-апреле 2020 г.: профицит бюджета обеспечен за счет роста неналоговых доходов / С.Г. Белёв, Т.В. Тищенко // Экономическое развитие России. - 2020. T. 27. - №6. - С. 4-7.

2. Бизнес в условиях кризиса. Какие льготы положены для поддержки бизнеса в условиях кризиса [Электронный ресурс] - Режим доступа: https://its.1c.ru/anticrisis/priveleges (Дата обращения: 20.10.2020).

3. Бунина А. Ю. Оптимизация налогообложения в кризис / А.Ю. Бунина, Т.Н. Павлюченко // Modern Science. — 2020. — №4-3. C. $53-59$.

4. Гашенко И.В. Ключевые инструменты налогового администрирования в условиях модернизации российской экономики/ И.В. Гашенко, Ю.С. Зима, И.В. Оробинская // Аудит и финансовый анализ. - 2018. №4. - С. 6-11.

5. Гашенко И. В. Роль и значение налога на прибыль организаций в формировании налоговых доходов бюджета РФ / И.В. Гашенко, Ю.С. Зима, Б.В. Черский // В сборнике: Проблемы учета, анализа, аудита и статистики в условиях рынка. Ученые записки. Ростов-на-Дону, 2018. - С. 299-305. 
6. Дерюгин А.Н. Региональные бюджеты в январе-апреле 2020 г.: сокращение доходов стало неизбежным / А.Н. Дерюгин // Экономическое развитие России. - 2020. T. 27. - №6. - C. 101-104.

7. Джабраилов Ю. Налогообложение, влияние налогообложения на экономический рост, уровень инфляции и рынок труда / Ю. Джабраилов // Мировая экономика: проблемы безопасности. - 2019. - №4. - С. 50-55.

8. Ежегодная информация об исполнении федерального бюджета [Электронный ресурс] / Министерство Финансов Российской Федерации. - Режим доступа: https://minfin.gov.ru/ru/statistics/fedbud/ execute/?id_65=80041-yezhegodnaya_ informatsiya_ob_ispolnenii_federalnogo_ byudzhetadannye_s_1_yanvarya_2006_g (Дата обращения: 20.10 .2020$)$.

9. Колчин С.П. Особенности федерального бюджета на 2020 год / С.П. Колчин, Н.Ю. Глубокова // Финансовая жизнь. 2020. — №1. - C. 109-112.

10. Павлова Н.Ц. Практический анализ налогообложения предприятия: влияние налогообложения на финансовую результативность и оптимизацию налоговой нагрузки/ Н.Ц. Павлова, Б.С. Микуляева // Экономика и предпринимательство. - 2018 . №3 (92). - С. 1241-1243.

11. Смирнов И.Е. Приоритеты бюджета России 2020-2022 гг. / И.Е. Смирнов // Аудитор. - 2020. - T. 6. - №1. - С. 3-9.

12. Тагильиева Ю.С. Налогообложение малого бизнеса в условиях экономического кризиса (на примере салона n) / Ю.С. Тагильцева // Бенефициар. - 2017. — №7. C. $10-14$.

13. Федеральный бюджет Российской Федерации в 2020 г. [Электронный ресурс]/ Министерство Финансов Российской Федерации. - Режим доступа: https://minfin. gov.ru/ru/perfomance/budget/federal_budget/ budgeti/2020/ (Дата обращения: 20.10.2020).

14. Чередниченко Л.Г. «Стартовые» позиции бюджетной политики и основные показатели федерального бюджета на 20202022 годы / Л.Г. Чередниченко, А. 3. Селезнев // Друкеровский вестник. - 2020. №2(34). - C. 27-35.

15. Gashenko I. V. Risk-oriented approach to tax control for stabilization of financial systems of developing countries by the example of modern Russia / I. V. Gashenko, Y.S. Zima // In the book: The Future of the Global Financial System: Downfall or Harmony. Ser. «Lecture Notes in Networks and Systems». - Cham, Switzerland, 2019. - P. 932-938.

16. The Global Competitiveness Reports 2011-2019 [Electronic resource] / World Economic Forum. - URL: http://www3.weforum. org/docs/WEF_TheGlobalCompetitivenessReport2019.pdf (Date accessed: 20.10.2020).

\section{References}

1. Beljov S. G. Ispolnenie federal'nogo bjudzheta v janvare-aprele 2020 g.: proficit bjudzheta obespechen za schet rosta nenalogovyh dohodov [Execution of the Federal budget in January-April 2020: the budget surplus is provided due to the growth of non-tax revenues] / S. G. Beljov, T. V. Tishhenko // Jekonomicheskoe razvitie Rossii [Economic development of Russia]. — 2020. — Vol. 27. — №6. - Pp. 4-7.

2. Biznes v uslovijah krizisa. Kakie l'goty polozheny dlja podderzhki biznesa $\mathrm{v}$ uslovijah krizisa [Business in crisis conditions. What benefits are required to support business in a crisis] [Jelektronnyj resurs] — URL: https:// its.1c.ru/anticrisis/priveleges (Date accessed: 20.10.2020).

3. Bunina A. Ju. Optimizacija nalogooblozhenija $\mathrm{v}$ krizis [Optimization of taxation in the crisis] / A. Ju. Bunina, T. N. Pavljuchenko// Modern Science. - 2020. — №4-3. - Pp. 53-59.

4. Gashenko I. V. Kljuchevye instrumenty nalogovogo administrirovanija v uslovijah modernizacii rossijskoj jekonomiki [The key tools of tax administration in the conditions of modernization of Russian economy] / I. V. Gashenko, Ju. S. Zima, I. V. Orobinskaja // Audit i finansovyj analiz [Audit and financial analysis]. — 2018. №4. - Pp. 6-11.

5. Gashenko I. V. Rol' i znachenie naloga na pribyl' organizacij v formirovanii nalogovyh dohodov bjudzheta RF [The role and importance of tax on profit of organizations in the formation of tax revenues of the Russian Federation] / I. V. Gashenko, Ju. S. Zima, B. V. Cherskij // V sbornike: Problemy ucheta, analiza, audita i statistiki $\mathrm{v}$ uslovijah rynka. Uchenye zapiski [In the book: problems of accounting, analysis, audit and statistics in market condi- 
tions. Scientific notes]. - Rostov-on-Don, 2018. - Pp. 299-305.

6. Derjugin A.N. Regional'nye bjudzhety v janvare-aprele 2020 g.: sokrashhenie dohodov stalo neizbezhnym [Regional budgets in JanuaryApril 2020: revenue reduction became inevitable/ A. N. Derjugin] // Jekonomicheskoe razvitie Rossii [Economic development of Russia]. 2020. — Vol. 27. — №6. - Pp. 101-104.

7. Dzhabrailov Ju. Nalogooblozhenie, vlijanie nalogooblozhenija na jekonomicheskij rost, uroven' infljacii i rynok truda [Taxation, the impact of taxation on economic growth, the level of inflation and the labor market] / Ju.Dzhabrailov// Mirovaja jekonomika: problemy bezopasnosti [World economy: security problems]. - 2019. — №4. - Pp. 50-55.

8. Ezhegodnaja informacija ob ispolnenii federal'nogo bjudzheta [Annual information on the execution of the Federal budget] [Jelektronnyj resurs] / Ministerstvo Finansov Rossijskoj Federacii [Ministry of Finance of the Russian Federation]. — URL: https://minfin.gov.ru/ru/ statistics/fedbud/execute/?id_65=80041-yezhegodnaya_informatsiya_ob_ispolnenii_federalnogo_byudzhetadannye_s_1_yanvarya_2006_g (Date accessed: 20.10.2020).

9. Kolchin S.P. Osobennosti federal'nogo bjudzheta na 2020 god [Features of the Federal budget for 2020] / S.P. Kolchin, N. Ju. Glubokova // Finansovaja zhizn' [Financial life]. 2020. — №1. — Pp. 109-112.

10. Pavlova N.C. Prakticheskij analiz nalogooblozhenija predprijatija: vlijanie nalogooblozhenija na finansovuju rezul'tativnost' i optimizaciju nalogovoj nagruzki [Practical analysis of enterprise taxation: the impact of taxation on financial performance and optimization of the tax burden]/ N.C. Pavlova, B.S. Mikuljaeva // Jekonomika i predprinimatel'stvo [Economics and entrepreneurship]. — 2018. — №3 (92). — Pp. 1241-1243.
11. Smirnov I.E. Prioritety bjudzheta Rossii 2020-2022 gg. [Priorities of the budget of Russia 2020-2022] / I.E. Smirnov // Auditor. 2020. - Vol. 6. — №1. - Pp. 3-9.

12. Tagil'ceva Ju. S. Nalogooblozhenie malogo biznesa $\mathrm{v}$ uslovijah jekonomicheskogo krizisa (na primere salona $\mathrm{n}$ ) [Taxation of small businesses in the context of the economic crisis (on the example of salon $\mathrm{n}$ )] / Ju. S. Tagil'ceva// Beneficiar [Beneficiary]. — 2017. — №7. Pp. 10-14.

13. Federal'nyj bjudzhet Rossijskoj Federacii v 2020 g. [Federal budget of the Russian Federation in 2020] [Jelektronnyj resurs] / Ministerstvo Finansov Rossijskoj Federacii [Ministry of Finance of the Russian Federation]. - URL: https://minfin.gov.ru/ru/perfomance/budget/ federal_budget/budgeti/2020/ (Date accessed: 20.10.2020).

14. Cherednichenko L. G. «Startovye»pozicii bjudzhetnoj politiki i osnovnye pokazateli federal'nogo bjudzheta na 2020-2022 gody [«Starting》 positions of the budget policy and the main indicators of the Federal budget for 2020-2022] / L.G. Cherednichenko, A.Z. Seleznev // Drukerovskij vestnik [Drucker's Bulletin]. - 2020. — №2 (34). — Pp. 27-35.

15. Gashenko I. V. Risk-oriented approach to tax control for stabilization of financial systems of developing countries by the example of modern Russia / I. V. Gashenko, Y.S. Zima // In the book: The Future of the Global Financial System: Downfall or Harmony. Ser. «Lecture Notes in Networks and Systems». - Cham, Switzerland, 2019. - P. 932-938.

16. The Global Competitiveness Reports 2011-2019 [Electronic resourse] / World Economic Forum. - URL: http://www3.weforum. org/docs/WEF TheGlobalCompetitivenessReport2019.pdf (Date accessed: 20.10.2020). 


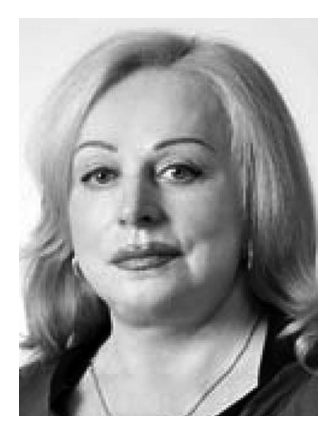

Гашенко Ирина Владиленовна - доктор экономических наук, профессор кафедры «Налоги и налогообложение» Ростовского государственного экономического университета (РИНХ). Специалист в области исследования проблемных аспектов прямого налогообложения. Советник государственной гражданской службы РФ I класса. Награждена знаком отличия «Отличник Министерства Российской Федерации по налогам и сборам». Общий стаж работы на руководящих должностях в налоговых органах составляет 25 лет, стаж преподавательской работы в университете - более 19 лет.

Gashenko Irina Vladilenovna - Doctor of Economic Sciences, Professor of the Department of Taxes and Taxation, Rostov State University of Economics (RSUE). Advisor to the State Civil Service of the Russian Federation, 1st class Awarded with the distinction «Excellent worker of the Ministry of the Russian Federation for Taxes and Duties». The total work experience in management positions in the tax authorities is 25 years, the experience of teaching at the university is over 19 years.

344002, г. Ростов-на-Дону, ул. Б. Садовая, 69 69 B. Sadovaya st., 344002, Rostov-on-Don, Russia E-mail: gaforos@rambler.ru

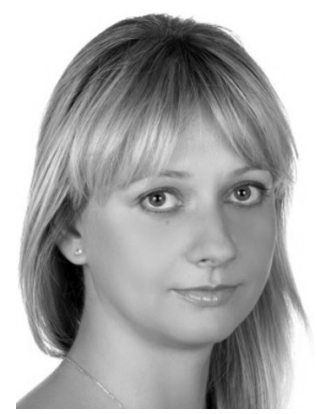

Зима Юлия Сергеевна - кандидат экономических наук, доцент кафедры «Налоги и налогообложение» Ростовского государственного экономического университета (РИНХ). Специалист в области исследования проблем и перспектив налогообложения юридических и физических лиц. Общий преподавательский стаж - 20 лет.

Zima Yulia Sergeevna - Candidate of Economic Sciences, Associate Professor of the Department of Taxes and Taxation, Rostov State University of Economics (RSUE). Specialist in the field of researching the problems and prospects of taxation of legal entities and individuals. General teaching experience for 20 years.

344002, г. Ростов-на-Дону, ул. Б. Садовая, 69

69 B. Sadovaya st., 344002, Rostov-on-Don, Russia

E-mail: zima.julia.sergeevna@gmail.com 


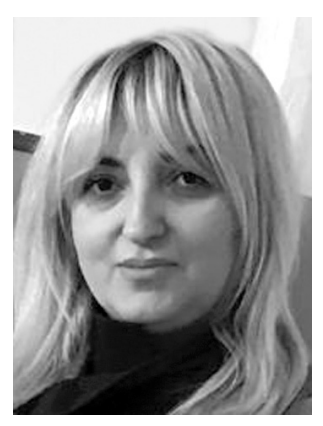

Мусаелян Анжелика Капреловна - кандидат экономических наук, заведующая кафедрой «Налоги и налогообложение» Ростовского государственного экономического университета (РИНХ). Специалист в области исследования инструментов налогового администрирования. Соисполнитель регионального проекта «Популяризация предпринимательства». Общий преподавательский стаж - более 20 лет.

Musaelyan Anzhelika Kaprelovna - Candidate of Economic Sciences, Head of the Department of Taxes and Taxation, Rostov State University of Economics (RSUE). Specialist in the field of tax administration research. Co-executor of the regional project «Popularization of Entrepreneurship».

344002, г. Ростов-на-Дону, ул. Б. Садовая, 69 69 B. Sadovaya st., 344002, Rostov-on-Don, Russia

E-mail: anjelika-rsue@yandex.ru 